\title{
Factors associated with depression in people with epilepsy: a retrospective case-control analysis
}

\author{
PH Ho, William CY Leung, lan YH Leung, Richard SK Chang*
}

\section{A B S T R A C T}

Purpose: This study investigated factors associated with depression in people with epilepsy.

Methods: All adult patients attending our epilepsy clinic in 2018 were screened for inclusion in this study. Eligible patients were divided into case and control groups, depending on the presence of co-morbid depression. Depressive disorders were diagnosed by a psychiatrist. Demographics and clinical characteristics, including epilepsy features and antiepileptic drug use, were compared between groups. The factors contributing to onset of depression after diagnosis of epilepsy were further analysed by binomial logistic regression. Statistical significance was set at $\mathrm{P}<0.05$.

Results: Forty four patients with epilepsy who had depression and 514 patients with epilepsy who did not have depression were included in this study (occurrence rate $=7.9 \%)$. Female sex $(\mathrm{P}=0.005)$, older age $(\mathrm{P}<0.001)$, temporal lobe epilepsy $(\mathrm{P}=0.01)$, and higher number of antiepileptic drugs used $(\mathrm{P}=0.003)$ were associated with depression in patients with epilepsy. No differences were observed in other epilepsy-related factors including aetiology, seizure
This article was published on 2 Jul 2020 at www.hkmj.org. odds ratio $[\mathrm{OR}]=3.56)$, drug-resistant epilepsy $(\mathrm{P}<0.001 ; \mathrm{OR}=4.79)$, and clonazepam use $(\mathrm{P}<0.001$; $\mathrm{OR}=14.41)$ were significantly positively associated with risk of depression after epilepsy diagnosis, whereas valproate use $(\mathrm{P}=0.03 ; \mathrm{OR}=0.37)$ was significantly negatively associated with risk of depression.

Conclusion: Female sex, refractoriness, and clonazepam use may be risk factors for depression after epilepsy diagnosis. Valproate may protect against depression in people with epilepsy. Better understanding of clinical features may aid in medical management or research studies regarding co-morbid depression in people with epilepsy.

\begin{tabular}{l} 
Hong Kong Med J 2020;26:311-7 \\
\hline https://doi.org/10.12809/hkmj198310 \\
${ }^{1}$ PH Ho, MB, BS \\
${ }^{2}$ WCY Leung, MRCP (UK) \\
${ }^{2}$ IYH Leung, MRCP (UK) \\
${ }^{2}$ RSK Chang *, FHKCP \\
${ }^{1}$ Department of Medicine, Queen Mary Hospital, Hong Kong \\
${ }^{2}$ Division of Neurology, Department of Medicine, Queen Mary Hospital, \\
Hong Kong \\
* Corresponding author: changsk@ha.org.hk
\end{tabular}

New knowledge added by this study

- This retrospective study investigated factors associated with depression in people with epilepsy, including a subgroup of patients who experienced depression onset after epilepsy diagnosis.

- Female sex, drug-resistant epilepsy, and clonazepam use were significantly positively associated with depression in people with epilepsy.

- Valproate use was significantly negatively associated with depression in people with epilepsy.

Implications for clinical practice or policy

- Clinicians who treat patients with epilepsy should be aware of the potential for co-morbid depression, especially in patients with potential risk factors (eg, female sex, drug-resistant epilepsy, and temporal lobe epilepsy).

- Psychotropic properties of antiepileptic drugs should be carefully considered when choosing treatment agents for people with epilepsy; clonazepam may promote depression, whereas valproate may protect against depression.

\section{Introduction}

People with epilepsy are susceptible to psychiatric disorders. Depression is arguably the most common psychiatric co-morbidity, which affects approximately $25 \%$ to $30 \%$ of people with epilepsy. ${ }^{1,2}$ Depression disorders increase the risk of suicide among people with epilepsy. ${ }^{3}$ Notably, co-morbid depression can greatly impact clinical outcomes and quality of life for people with epilepsy. ${ }^{4}$
The relationship between epilepsy and depression is more complex than simple psychological stress related to chronic illness. Structural and functional changes in the brain may explain the underlying pathogenic mechanism. ${ }^{5,6}$ Furthermore, people with epilepsy who exhibit co-morbid depression also demonstrate worse seizure control, compared with people with epilepsy who do not have depression. ${ }^{7}$ Suboptimal drug 


\section{腦癇患者抑缶症症的相關因素：回顧性病例}

\section{對照分析}

何沛鴻、梁俊彥、梁宇軒、張錫坤

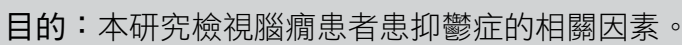

方法：本研究對瑪麗醫院所有腦癇診所的成年患者進行篩查。符合條 件的患者被分為病例組和對照組。抑鬱症須由精神科醫生診斷。我們 比較兩組的人口統計和臨床特徵, 包括腦痟症特徵和使用抗疰藥藥 史。我們透過二項式䍜輯迴歸進一步分析腦痛診斷後出現抑鬱症的因 素。 $\mathrm{P}<0.05$ 表示統計的顯著性。

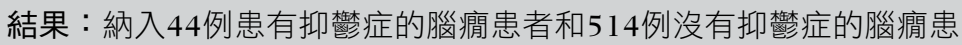
者（發生率 $=7.9 \%)$ 。女性（ $\mathrm{P}=0.005 ）$ 、較大年紀（ $\mathrm{P}<0.001 ）$

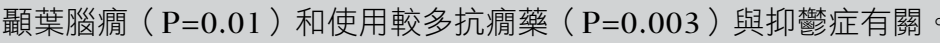
其他因素包括病因、腦疡發作類型和腦癇病灶的偏側性則沒有差異。 二項式邏輯迴歸分析顯示女性（P=0.01；比值比 $=3.56)$ 、難治性 腦痭 $(\mathrm{P}<0.001$; 比值比 $=4.79)$ 和使用氯硝西泮 $(\mathrm{P}<0.001$; 比值

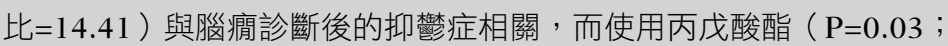

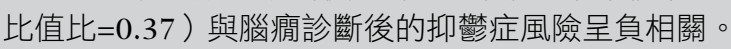

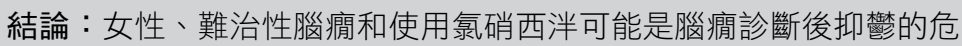

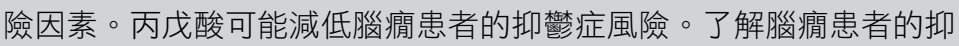

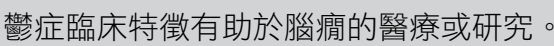

adherence and higher rates of adverse effects from antiepileptic drugs (AEDs) have also been reported among people with epilepsy who exhibit co-morbid depression..$^{8,9}$

As discussed in a recent systematic review, many studies have attempted to evaluate the roles of various epilepsy-related factors in the onset of depression; however, most showed no associations with depression or demonstrated inconsistent results. ${ }^{10}$ The present study was performed to investigate the relationships of clinical factors, including use of AEDs, with depression in people with epilepsy.

\section{Methods}

\section{Patients and study design}

This was a retrospective study. All adult patients, aged $\geq 18$ years, attending the epilepsy clinic of Queen Mary Hospital, Hong Kong, from January to December 2018, were screened for inclusion in the study. Relevant data were retrieved from the computerised medical records system. Diagnoses of epilepsy were made or confirmed by a neurologist. Patients with both epilepsy and depression were included in the case group, while those with epilepsy alone were included in the control group. Depression was defined as the presence of depressive disorders as described in the International Classification of Diseases 10th Revision, diagnosed by a psychiatrist.
Patients with intellectual disability were excluded due to potential difficulties in determining diagnoses of mood disorders in this group ${ }^{11}$; patients with other psychiatric disorders were also excluded to avoid confounding effects.

\section{Collection of data}

The following data were collected from medical records: basic demographic characteristics, epilepsy and depression details, and use of AEDs. Major neurological and medical conditions that had been present before the epilepsy and depression diagnoses were also recorded. The categorisation of epilepsy was performed in accordance with the International League Against Epilepsy 2017 classification scheme. ${ }^{12}$ Patients were determined to have drugresistant epilepsy when adequate trials of two tolerated, appropriately chosen, and appropriately used AED schedules (whether as monotherapies or in combination) failed to achieve sustained seizure freedom. ${ }^{13}$ Seizure freedom was defined as the absence of seizures for 1 year. Seizure type, location, and laterality of epileptic focus were determined by seizure semiology, any previous neuroimaging findings, and electroencephalography results. Locations of epileptic foci were classified according to cerebral lobes. Any AED used for $>6$ months was recorded in this analysis; the maximum number of AEDs used was also recorded. This study followed the STROBE guidelines for study reporting. ${ }^{14}$

\section{Statistical analysis}

Clinical features were compared between the groups with and without co-morbid depression. The Chi squared test was used to detect statistically significant differences in categorical data, and the $t$ test was used to detect any statistically significant differences in continuous data. Sample size was based on the existing patient number during the study period; thus, no sample size calculations were performed.

To investigate the effects of AEDs on development of depression in people with epilepsy, further analysis was performed regarding the subgroup of patients in whom depression was diagnosed after epilepsy onset. In particular, patients were selected for whom depression diagnosis occurred in the calendar year (or later) after the year of epilepsy diagnosis. Relevant factors, particularly use of AEDs, were analysed for their predictive value in terms of depression development, using binomial logistic regression. Variables were entered into the regression model by forward selection, based on likelihood ratios. Statistical analyses were carried out using SPSS Statistics for Windows (version 25.0; IBM Corp, Armonk [NY], United States). Statistical significance was set at $\mathrm{P}<0.05$. 


\section{Results}

\section{Patient characteristics}

Forty four patients with epilepsy who had co-morbid depression were selected as the case group, while 558 patients with epilepsy who did not exhibit depression were selected as the control group; the patient characteristics are summarised in Table 1. Among the patients with co-morbid depression, $32(73 \%)$ experienced onset of epilepsy before the diagnosis of depression, while $12(27 \%)$ had a diagnosis of depression before the onset of epilepsy; furthermore, 14 (32\%) exhibited drug-resistant epilepsy. Most patients with co-morbid depression had a diagnosis of major depression $(36 / 44,82 \%)$; of the remaining eight patients, one (2\%) had dysthymia, two (5\%) had mixed anxiety and depressive disorder, and five (11\%) had a diagnosis of unspecified depression. The mean age ( \pm standard deviation) at depression diagnosis was $46 \pm 13$ years, while the

TABLE I. Clinical features of patients with epilepsy, with or without co-morbid depression*

\begin{tabular}{|c|c|c|c|}
\hline Clinical features & $\begin{array}{l}\text { Patients with co-morbid } \\
\text { depression }(n=44)\end{array}$ & $\begin{array}{l}\text { Patients without co-morbid } \\
\text { depression }(n=514)\end{array}$ & $P$ value \\
\hline \multicolumn{4}{|l|}{ Basic demographics } \\
\hline Female sex & $30(68.2 \%)$ & $237(46.1 \%)$ & 0.005 \\
\hline Mean age at data collection (years) & $58.9 \pm 10.7$ & $51.3 \pm 15.8$ & 0.001 \\
\hline Mean age at epilepsy diagnosis (years) & $35.2 \pm 18.6$ & $32.4 \pm 19.2$ & 0.726 \\
\hline $\begin{array}{l}\text { Duration of epilepsy diagnosis at data } \\
\text { collection (years) }\end{array}$ & $22.7 \pm 15.4$ & $17.9 \pm 12.1$ & 0.003 \\
\hline \multicolumn{4}{|l|}{ Epilepsy details } \\
\hline Aetiology of epilepsy & & & 0.858 \\
\hline Genetic & $4(9.1 \%)$ & $69(13.4 \%)$ & \\
\hline Unknown & $26(59.1 \%)$ & $289(56.2 \%)$ & \\
\hline Structural or metabolic & $14(31.8 \%)$ & $155(30.2 \%)$ & \\
\hline Unspecified & 0 & $1(0.2 \%)$ & \\
\hline Seizure type & & & 0.370 \\
\hline Focal aware seizure & $1(2.3 \%)$ & $15(2.9 \%)$ & \\
\hline Focal impaired awareness seizure & $40(90.9 \%)$ & $414(80.5 \%)$ & \\
\hline Generalised onset seizure & $3(6.8 \%)$ & $78(15.2 \%)$ & \\
\hline Unspecified & 0 & $7(1.4 \%)$ & \\
\hline \multicolumn{4}{|l|}{ Location of epileptic focus/foci† } \\
\hline Frontal & 7 (15.9\%) & $64(12.5 \%)$ & 0.509 \\
\hline Parietal & $2(4.5 \%)$ & $38(7.4 \%)$ & 0.760 \\
\hline Temporal & $19(43.2 \%)$ & $132(25.7 \%)$ & 0.012 \\
\hline Occipital & $2(4.5 \%)$ & $22(4.3 \%)$ & 1.000 \\
\hline Unknown or others & $18(40.9 \%)$ & $305(59.3 \%)$ & 0.017 \\
\hline Laterality of epileptic focus & & & 0.358 \\
\hline Right & $9(20.5 \%)$ & $88(17.1 \%)$ & \\
\hline Left & $11(25.0 \%)$ & $92(17.9 \%)$ & \\
\hline Unknown or others (including generalised) & $24(54.5 \%)$ & $334(65.0 \%)$ & \\
\hline Presence of drug-resistant epilepsy & $14(31.8 \%)$ & $119(23.2 \%)$ & 0.195 \\
\hline Seizure frequency (per month) & $1.39 \pm 2.67$ & $2.56 \pm 5.28$ & 0.237 \\
\hline Seizure-free duration (months) & $53.9 \pm 55.6$ & $74.3 \pm 66.1$ & 0.272 \\
\hline History of status epilepticus & $1(2.3 \%)$ & $31(6.0 \%)$ & 0.500 \\
\hline Previous epilepsy surgery & 0 & $6(1.2 \%)$ & 1.000 \\
\hline Family history of epilepsy & $2(4.5 \%)$ & $14(2.7 \%)$ & 0.364 \\
\hline Maximum No. of AEDs at one time & $2.41 \pm 1.40$ & $1.73 \pm 1.08$ & 0.003 \\
\hline
\end{tabular}

Abbreviation: AED = antiepileptic drug

* Data are presented as No. (\%) or mean \pm standard deviation, unless otherwise specified

$\dagger$ Some patients had multiple epileptic foci located in different lobes 
mean age at epilepsy diagnosis was $35 \pm 19$ years. The mean duration between onset of epilepsy and diagnosis of co-morbid depression was $13 \pm 13$ years. Most patients with epilepsy who had co-morbid depression did not exhibit other major neurological $(36 / 44,82 \%)$ or medical conditions $(41 / 44,93 \%)$. Of the remaining eight patients with major neurological conditions, six (14\%) had stroke, one (2\%) had traumatic brain injury, and one (2\%) had migraine. Of the remaining three patients with major medical conditions, two (5\%) had malignancy and one (2\%) had rheumatoid arthritis. Notably, one patient had both stroke and malignancy, while another patient had both stroke and rheumatoid arthritis.

\section{Comparison between case and control groups}

Clinical features were compared between the case and control groups (Table 1). Patients with depression were older and included more women. A significantly longer duration of epilepsy was observed in patients with depression; however, the mean age at epilepsy onset did not significantly differ between the groups. Temporal lobe epilepsy was more common in patients with depression; moreover, patients with depression used a greater mean number of AEDs. No differences were noted in other epilepsy-related factors, including family history, drug-resistant disease, seizure frequency, aetiology, seizure type, or history of status epilepticus. Laterality in focal epilepsy also showed no association with co-morbid depression.

\section{Subgroup analysis of patients in whom depression was diagnosed after epilepsy onset}

Relevant parameters were selectively included in binomial logistic regression analysis to determine risk factors for co-morbid depression (Table 2). The relevant parameters depended on statistical results in the whole group analysis and clinical judgement. Parameters that reached statistically significance in the whole group analysis were selected. Other parameters considered as clinically important were included as well. Only patients in whom depression was diagnosed after epilepsy onset were included in this analysis. Female sex, drug-resistant epilepsy,

TABLE 2. Risk factors for co-morbid depression, identified by binomial logistic regression analysis

\begin{tabular}{lcc}
\hline Factors & $\begin{array}{c}\text { Odds ratio (95\% } \\
\text { confidence interval) }\end{array}$ & P value \\
\hline Female sex & $3.56(1.36-9.36)$ & 0.010 \\
Drug-resistant epilepsy & $4.79(2.06-11.12)$ & $<0.001$ \\
Clonazepam use & $14.41(4.20-49.47)$ & $<0.001$ \\
Valproate use & $0.37(0.15-0.91)$ & 0.031 \\
\hline
\end{tabular}

and clonazepam use were significantly positively associated with a risk of co-morbid depression among patients with epilepsy. In contrast, valproate use was significantly negatively associated with a risk of co-morbid depression.

\section{Discussion}

Depression is one of the most common psychiatric co-morbidities among people with epilepsy. Our study involving a cohort of people with epilepsy revealed that $7.9 \%$ had depression; of these, $73 \%$ had epilepsy onset before depression diagnosis. This prevalence is much lower than the rate of approximately $30 \%$ previously described in previous studies of Western and Chinese populations ${ }^{15-17}$; differences in study design may explain this discrepancy. Previous studies were commonly questionnaire or scale-based; generally, they used the Hospital Anxiety and Depression Scale, Neurological Disorders Depression Inventory for Epilepsy, or Patient Health Questionnaire nine-item depression scale. ${ }^{18-20}$ Importantly, these different scales have respective strengths and limitations. ${ }^{21-23}$ In our study, the definition of depression was relatively stringent, because it was confirmed by a psychiatrist. Patients with co-existing psychiatric disorders (eg, psychotic disorders, substance abuse, and personality disorders) were deliberately excluded. Although the psychiatric profile in our cohort was relatively homogeneous because of the stringent criteria, patients with relatively minor or occult depressive symptoms might have been excluded. Importantly, the low prevalence of depression may indicate that this common affective disorder is often overlooked by clinicians in our locality. Underdiagnosis of psychiatric co-morbidities is a major problem encountered by people with epilepsy. ${ }^{24,25}$ Awareness of psychiatric co-morbidities, identified with the aid of assessment scales, may improve the sensitivity of diagnosis.

This study placed considerable emphasis on the temporal relationship between epilepsy and depression. A number of similar studies used a cross-sectional design, which present a methodological problem regarding the unclear temporal relationship between epilepsy and co-morbid depression. ${ }^{6}$ Extraction of data from clinical records allows assessment of an individual patient's clinical features at different timepoints. In the present study, only patients with depression onset after epilepsy diagnosis were included in logistic regression analysis, which enables clearer assessment of the relationship between epilepsy and co-morbid depression.

In our study, patients with epilepsy who exhibited depression were predominantly women. This finding is consistent with the results of a previous systemic review. ${ }^{10}$ Female sex predominance has also 
been observed in studies of depression alone. ${ }^{26,27}$ In the present study, patients with depression were older and had a longer duration of epilepsy diagnosis, presumably because of accumulation bias. The mean interval for development of depression was 13 years after epilepsy onset; however, age at epilepsy onset was not associated with development of depression. It remains controversial whether younger epilepsy onset age is related to a higher risk of subsequent depression. Some studies have shown positive associations, whereas others have not. ${ }^{28,29}$

Previous evidence suggested that focal epilepsy, rather than generalised epilepsy, was associated with co-morbid depression in people with epilepsy. ${ }^{15,30,31}$ This finding was not observed in our study; however, temporal lobe epilepsy was significantly more prevalent in patients with depression. The underlying pathogenic mechanism may involve the close relationship of the temporal lobe with the limbic system, which plays a key role in emotional control. Frequent epileptic focus discharge can lead to reduced blood flow and metabolism in corresponding cerebral regions. ${ }^{5,32}$ Furthermore, temporal lobe epilepsy is associated with hippocampal damage and atrophy, typically comprising hippocampal sclerosis. ${ }^{33}$ Temporal lobe hypometabolism and hippocampal volume loss have also been implicated in depression. ${ }^{34,35}$ Finally, an association of depression with epileptic foci in frontal and left temporal lobes has also been reported, ${ }^{31}$ but this phenomenon was not observed in our cohort.

In our study, drug-resistant epilepsy was associated with depression in binomial logistic regression analysis, but not when analysis was performed using the Chi squared test. In this study, patients included in analysis by the Chi squared test had depression either before or after the diagnosis of epilepsy. In contrast, the binomial logistic regression model only included patients in whom depression was diagnosed after epilepsy onset. Additionally, the exact seizure frequency did not affect the risk of depression in this study; conversely, seizure frequency was associated with co-morbid depression in a previous systemic review. ${ }^{10}$ This discrepancy may be explained by differences in sample composition. However, it remains unclear whether better epilepsy control (ie, seizure frequency reduction) will alleviate the risk of depression.

Use of AEDs also contributes to the onset of mood disorder in people with epilepsy. This study showed that clonazepam use was positively associated with risk of depression in people with epilepsy; conversely, valproate use was negatively associated with risk of depression. The impact of AEDs on psychiatric illness has been extensively studied. Benzodiazepines, including clonazepam, have been proposed to induce depression by overinhibition of the GABAergic pathway. ${ }^{31,36}$
Valproate, carbamazepine, and lamotrigine are examples of AEDs with positive psychotropic effects, whereas benzodiazepine, levetiracetam, phenobarbital, and topiramate exhibit negative psychotropic effects. ${ }^{37-40}$

The findings of this study have a few important implications for clinical practice. First, the recognition of depression in people with epilepsy can be challenging for clinicians, especially in a busy out-patient clinic setting. ${ }^{24}$ The identification of at-risk patients is essential for improving the diagnostic yield of affective disorders among people with epilepsy. Female sex, drug-resistant epilepsy, and temporal lobe epilepsy may be associated with co-morbid depression. Clinicians should be vigilant in searching for depressive features in patients with these characteristics during clinical consultation.

Second, the use of AEDs plays a role in co-morbid depression in people with epilepsy. Psychotropic properties of AEDs should be carefully considered when choosing treatment agents for people with epilepsy, especially for patients who are at risk of depression (eg, women, patients with drug-resistant epilepsy, and patients with temporal lobe epilepsy). Clonazepam (ie, a benzodiazepine) has been associated with depression onset in people with epilepsy; in contrast, valproate may have a protective effect against depression onset in people with epilepsy. This could be due to the moodstabilising effect of valproate, which has led to its use for treatment of patients with manic disorder. Antiepileptic drugs can have a considerable impact on quality of life in people with epilepsy, in addition to their seizure control effects. The impact of newergeneration AEDs requires further analysis, because these drugs were inadequately represented among the limited number of patients in the current study.

There were some limitations in this study. First, there were inherent limitations due to the retrospective nature of the analysis. In particular, the information documented in medical records may not be uniform and may be subject to recall bias. Second, the diagnosis of depression in our study tended to be stringent, because it relied on a psychiatrist's diagnosis, instead of more widely used assessment tools (eg, depressive scales). However, this approach may have led to underestimation regarding the extent of depressive disorders among patients in this cohort. Third, the AEDs were required to be used for $>6$ months to be included in the analysis. However, the durations, dosages, or serum drug levels of AEDs were not considered, because they may have varied during the course of epilepsy. Fourth, relatively few socio-economic and psychological factors were included in this analysis. Some previous studies showed that these factors were associated with co-morbid depression; however, they have been less frequently investigated than other epilepsy-related 
factors (eg, employment, marital status, and stressful life events). ${ }^{1}$ Further prospective studies that include examinations of these psychosocial factors may provide more complete information regarding depression in people with epilepsy.

\section{Conclusions}

Depression is a common mood disorder in people with epilepsy. This study showed that depression tends to affect a subgroup of people with epilepsy who exhibit specific demographic and epilepsy-related factors. Notably, the use of AEDs may also influence the risk of depression in people with epilepsy. This study may contribute to better understanding of clinical features, thereby aiding in future clinical management or basic science studies regarding co-morbid depression in people with epilepsy.

\section{Author contributions}

Concept or design: PH Ho.

Acquisition of data: PH Ho, RSK Chang.

Analysis or interpretation of data: PH Ho, RSK Chang.

Drafting of the manuscript: PH Ho, RSK Chang.

Critical revision of the manuscript for important intellectual content: All authors.

All authors had full access to the data, contributed to the study, approved the final version for publication, and take responsibility for its accuracy and integrity.

\section{Conflicts of interest}

The authors have no conflicts of interest to disclose.

\section{Declaration}

This research was presented as a poster presentation titled "Clinical features and predictors of depression in people with epilepsy (PWE)" at the 33rd International Epilepsy Congress, Bangkok, 22-26 June 2019.

\section{Funding/support}

This research received no specific grant from any funding agency in the public, commercial, or not-for-profit sectors.

\section{Ethics approval}

This study was approved by the Hospital Authority Hong Kong West Cluster Institutional Review Board (Ref UW 19-742). The need for informed consent was waived.

\section{References}

1. Hermann BP, Seidenberg M, Bell B. Psychiatric comorbidity in chronic epilepsy: identification, consequences, and treatment of major depression. Epilepsia 2000;41 Suppl 2:S31-41

2. Asadi-Pooya AA, Kanemoto K, Kwon OY, et al. Depression in people with epilepsy: how much do Asian colleagues acknowledge it? Seizure 2018;57:45-9.

3. Kanner AM. Depression and epilepsy: a new perspective on two closely related disorders. Epilepsy Curr 2006;6:1416.
4. Lehrner J, Kalchmayr R, Serles W, et al. Health-related quality of life (HRQOL), activity of daily living (ADL) and depressive mood disorder in temporal lobe epilepsy patients. Seizure 1999;8:88-92.

5. Bromfield EB, Altshuler L, Leiderman DB, et al. Cerebral metabolism and depression in patients with complex partial seizures. Arch Neurol 1992;49:617-23.

6. Kanner AM, Schachter SC, Barry JJ, et al. Depression and epilepsy: epidemiologic and neurobiologic perspectives that may explain their high comorbid occurrence. Epilepsy Behav 2012;24:156-68.

7. Hitiris N, Mohanraj R, Norrie J, Sills GJ, Brodie MJ. Predictors of pharmacoresistant epilepsy. Epilepsy Res 2007;75:192-6.

8. Ettinger $A B$, Good MB, Manjunath R, Edward Faught R, Bancroft $T$. The relationship of depression to antiepileptic drug adherence and quality of life in epilepsy. Epilepsy Behav 2014;36:138-43.

9. Cramer JA, Blum D, Reed M, Fanning K, Epilepsy Impact Project Group. The influence of comorbid depression on quality of life for people with epilepsy. Epilepsy Behav 2003;4:515-21.

10. Lacey CJ, Salzberg MR, D'Souza WJ. Risk factors for depression in community-treated epilepsy: systematic review. Epilepsy Behav 2015;43:1-7.

11. Walton C, Kerr M. Severe intellectual disability: systematic review of the prevalence and nature of presentation of unipolar depression. J Appl Res Intellect Disabil 2016;29:395-408.

12. Scheffer IE, Berkovic S, Capovilla G, et al. ILAE classification of the epilepsies: position paper of the ILAE Commission for Classification and Terminology. Epilepsia 2017;58:512-21.

13. Kwan P, Arzimanoglou A, Berg AT, et al. Definition of drug resistant epilepsy: consensus proposal by the ad hoc Task Force of the ILAE Commission on Therapeutic Strategies. Epilepsia 2010;51:1069-77.

14. Equator Network. The Strengthening the Reporting of Observational Studies in Epidemiology (STROBE) Statement: guidelines for reporting observational studies. Available from: http://www.equator-network.org. Accessed 15 Nov 2019.

15. Chen K, Pan Y, Xu C, Wu W, Li X, Sun D. What are the predictors of major depression in adult patients with epilepsy? Epileptic Disord 2014;16:74-9.

16. Tellez-Zenteno JF, Patten SB, Jetté N, Williams J, Wiebe S. Psychiatric comorbidity in epilepsy: a population-based analysis. Epilepsia 2007;48:2336-44.

17. Kwong KL, Lam D, Tsui S, et al. Anxiety and depression in adolescents with epilepsy. J Child Neurol 2016;31:203-10.

18. Alsaadi T, El Hammasi K, Shahrour TM, et al. Depression and anxiety among patients with epilepsy and multiple sclerosis: UAE comparative study. Behav Neurol 2015;2015:196373.

19. Azuma H, Akechi T. Effects of psychosocial functioning, depression, seizure frequency, and employment on quality of life in patients with epilepsy. Epilepsy Behav 2014;41:1820.

20. Mohamed S, Gill JS, Tan CT. Quality of life of patients with epilepsy in Malaysia. Asia Pac Psychiatry 2014;6:105-9.

21. Mitchell AJ, Meader N, Symonds P. Diagnostic validity of the Hospital Anxiety and Depression Scale (HADS) in cancer and palliative settings: a meta-analysis. J Affect 
Disord 2010;126:335-48.

22. Kim DH, Kim YS, Yang TW, Kwon OY. Optimal cutoff score of the Neurological Disorders Depression Inventory for Epilepsy (NDDI-E) for detecting major depressive disorder: a meta-analysis. Epilepsy Behav 2019;92:61-70.

23. Hartung TJ, Friedrich M, Johansen C, et al. The Hospital Anxiety and Depression Scale (HADS) and the 9-item Patient Health Questionnaire (PHQ-9) as screening instruments for depression in patients with cancer. Cancer 2017;123:4236-43.

24. O'Donoghue MF, Goodridge DM, Redhead K, Sander JW, Duncan JS. Assessing the psychosocial consequences of epilepsy: a community-based study. Br J Gen Pract 1999;49:211-4

25. Boylan LS, Flint LA, Labovitz DL, Jackson SC, Starner K, Devinsky O. Depression but not seizure frequency predicts quality of life in treatment-resistant epilepsy. Neurology 2004;62:258-61.

26. Çakıcı M, Gökçe Ö, Babayiğit A, Çakıcı E, Eş A. Depression: point-prevalence and risk factors in a North Cyprus household adult cross-sectional study. BMC Psychiatry 2017;17:387.

27. Lam LC, Wong CS, Wang MJ, et al. Prevalence, psychosocial correlates and service utilization of depressive and anxiety disorders in Hong Kong: the Hong Kong Mental Morbidity Survey (HKMMS). Soc Psychiatry Psychiatr Epidemiol 2015;50:1379-88.

28. Kanner AM, Barry JJ. The impact of mood disorders in neurological diseases: should neurologists be concerned? Epilepsy Behav 2003;4 Suppl 3:S3-13.

29. Lacey CJ, Salzberg MR, D'Souza WJ. What factors contribute to the risk of depression in epilepsy? Tasmanian Epilepsy Register Mood Study (TERMS). Epilepsia 2016;57:516-22.

30. Kimiskidis VK, Triantafyllou NI, Kararizou E, et al.
Depression and anxiety in epilepsy: the association with demographic and seizure-related variables. Ann Gen Psychiatry 2007;6:28.

31. Grabowska-Grzyb A, Jedrzejczak J, Nagańska E, Fiszer U. Risk factors for depression in patients with epilepsy. Epilepsy Behav 2006;8:411-7.

32. Victoroff JI, Benson F, Grafton ST, Engel J Jr, Mazziotta JC. Depression in complex partial seizures. Electroencephalography and cerebral metabolic correlates. Arch Neurol 1994;51:155-63.

33. Kälviäinen R, Salmenperä T, Partanen K, Vainio $P$, Riekkinen P, Pitkänen A. Recurrent seizures may cause hippocampal damage in temporal lobe epilepsy. Neurology 1998;50:1377-82.

34. Hosokawa T, Momose T, Kasai K. Brain glucose metabolism difference between bipolar and unipolar mood disorders in depressed and euthymic states. Prog Neuropsychopharmacol Biol Psychiatry 2009;33:243-50.

35. Bremner JD, Narayan M, Anderson ER, Staib LH, Miller HL, Charney DS. Hippocampal volume reduction in major depression. Am J Psychiatry 2000;157:115-8.

36. Luscher B, Shen Q, Sahir N. The GABAergic deficit hypothesis of major depressive disorder. Mol Psychiatry 2011;16:383-406.

37. Tao K, Wang X. The comorbidity of epilepsy and depression: diagnosis and treatment. Expert Rev Neurother 2016;16:1321-33.

38. Mula M, Agrawal N, Mustafa Z, et al. Self-reported aggressiveness during treatment with levetiracetam correlates with depression. Epilepsy Behav 2015;45:64-7.

39. Klufas A, Thompson D. Topiramate-induced depression. Am J Psychiatry 2001;158:1736.

40. Brent DA, Crumrine PK, Varma RR, Allan M, Allman C. Phenobarbital treatment and major depressive disorder in children with epilepsy. Pediatrics 1987;80:909-17. 